648

\section{THE COMPLEX PROBLEMS OF CHILDREN AND FAMILIES WITH A CHILD WITH DISORDERS OF SEXUAL DEVELOPMENT}

doi:10.1136/archdischild-2012-302724.0648

${ }^{1} \mathrm{OD}$ Marginean, ${ }^{2} \mathrm{TD}$ Marcovici, ${ }^{2} \mathrm{DM}$ Chiru. 'Pediatrics, University of Medicine and Pharmacy; ${ }^{2}$ Pediatrics, University of Medicine and Pharmacy 'Victor Babes', Timisoara, Romania

Background The diagnose of DSD is a challenge for medical staff, family and society.

Material and method We study 15 patients with DSD, between 2005-2011. The study protocol included anamnesis, clinical examination: auxiological dates, degree of puberty (Tanner), genitalia conformation (Prader stages) and its consistency with social sex. Laboratory datas: karyotype, gonadotrophins, testosterone, DHT, inhibin B, DHEA and DHEAS, $17 \mathrm{OH}$ progesterone; SRY gene (in selected cases) was performed. In all the cases we perform psychological exams of the child and family.

Results We have eight, $46 \mathrm{XX}$, and three $46 \mathrm{XY}$ subjects. According to age we have 4 groups: newborns (2), children between 1-3 years(4), between 3-6 years (6) and more than 10 years(2). The diagnosis was: CAH 8 cases, PAIS 1 case, Simith-Lemli-OptzSyndrome 1 case, Leyding cell hypoplasia 1 case. In neonatal period the correct assessment of social sex reveal minimal psychological familial problems. Adolescent CAH have general psychological distress higher rates of substance abuse, somatization, and suicidal behaviors. PAIS child want to change "her" sex because poorer social and interpersonal relationship functioning. The family doesn't agree because they live in a community with specific rules.

\section{Conclusions}

1. In DSD cases the assessment of sex must be done in neonatal period after careful evaluations of the child.

2. The psychological implications are more deep and affect the child, family and the society.

3. The right of the child must be protected by specific low of the state.

\section{A CASE OF PERMANENT NEONATAL DIABETES MELLITUS}

doi:10.1136/archdischild-2012-302724.0649

'Z Karabouta, ${ }^{2}$ S Ellard, ${ }^{3}$ SE Flanagan, ${ }^{4} \mathrm{D}$ Mackay, ${ }^{5} \mathrm{JP}$ Hamilton-Shield, ${ }^{1} \mathrm{~F}$ AthanassiadouPiperopoulou, 'I Rousso. '2nd Paediatric Department, AHEPA General University Hospital, Thessaloniki, Greece; ${ }^{2}$ Department of Molecular Genetics, Royal Devon \& Exeter NHS Hospital, Peninsula Medical School; 3Molecular Genetics, Peninsula College of Medicine and Dentistry, Exeter; "Wessex Regional Genetics Laboratory, Salisbury District Hospital, Salisbury; ${ }^{5}$ Department of Paediatric Endocrinology, Bristol Children's Hospital, Bristol, UK

Background and Aims Neonatal Dabetes Mellitus(NDM) is a rare(1/400,000 newborns) but potentially devastating condition. It has been defined as insulin-sensitive hyperglycemia that is diagnosed within the first six months of life and can be either transient(TNDM) or permanent(PNDM). PNDM has been linked to mutations in several different genes. TNDM is associated with defects in an imprinted region of the paternally derived chromosome 6 . We describe a baby boy four months old diagnosed with PNDM.

Methods The patient was admitted to hospital with diabetic ketoacidosis(blood sugar $>700 \mathrm{mg} / \mathrm{dl}(>38.8 \mathrm{mmol} / \mathrm{l}), \mathrm{pCO}_{2} 22 \mathrm{mmHg}$, $\left.\mathrm{pO}_{2} 107 \mathrm{mmHg}, \mathrm{HCO}_{3} 12.1 \mathrm{mmol} / \mathrm{l}\right)$. He had a preceding fortnight history of polyuria, polydipsia, lethargy and vomiting the last few days before admission. Clinically he was lethargic and dehydrated, with sunken fontanelle and eyes, reduced skin turgor, dry mucous membranes and had tachypnoea, ketotic breath. He was treated with intravenous fluids and insulin. Progressively he recovered and started feeding orally. He was discharged on daily insulin injections subcutaneously.

Results On admission glycated hemoglobin $\left(\mathrm{HbA}_{1} \mathrm{c}\right)$ was $5.8 \%$ (4.3-6.1\%), anti-GAD autoantibodies 1.3 (ratio $>1.1$ positive), IA2(tyrosine phosphatase antibodies) $1.2(<8 \mathrm{iu} / \mathrm{ml})$, IAA(anti-insulin antibodies) 1.50 (< 1.10 ratio), ICA(anti-islet antibodies) 0.5 (< 1.00 ratio), EMA(anti-endomysial antibodies) negative. Past medical and family history were unremarkable. Genetic testing for PNDM failed to detect any mutations in the KCNJ11, ABCC8 and INS genes, as well as the testing for abnormalities in the chromosome $6 \mathrm{q}$ for TNDM.

Conclusions Genetic testing for NDM can identify PNDM in newborns helping the physician to select the most appropriate therapy. However, $40 \%$ of cases are currently without a molecular genetic diagnosis.

\section{UMBILICAL CORD AND FIFTH DAY SERUM VASPIN CONCENTRATIONS IN SMALL, APPROPRIATE AND LARGE FOR GESTATIONAL AGE NEONATES}

doi:10.1136/archdischild-2012-302724.0650

'A Akcay, ${ }^{1} \mathrm{M}$ Akar, ${ }^{1} \mathrm{G}$ Demirel, ${ }^{1} \mathrm{FE}$ Canpolat, ${ }^{1} \mathrm{O}$ Erdeve, ${ }^{1,2} \mathrm{U}$ Dilmen. ${ }^{1}$ Neonatology, Zekai Tahir Burak Maternity and Teaching Hospital; '2Pediatrics, Yildirim Beyazit University, Faculty of Medicine, Ankara, Turkey

Background and Aim Vaspin is a visceral adipose tissue derived serin protease inhibitor which has an insulin sensitizing effect. It is correlated with insulin resistance and glucose metabolism and it improves glucose tolerance. Ou aim was to determine and compare serum vaspin and insulin concentrations in small-for-gestational age [SGA], appropriate-for-gestational age [AGA] and largefor-gestational age [LGA] infants at birth and fifth day of life.

Methods Eighty-two neonates were divided into three groups, as SGA [ $n=22]$, AGA [ $n=30]$ and LGA [ $n=30]$. Mothers age, gestational week, mode of delivery, maternal diseases like diabetes, preeclampsia and eclampsia were recorded. Blood for vaspin, insulin and glucose was collected from cord at birth and peripheric vein on the fifth day of life.

Results At birth, there were no statistically significant difference in serum insulin concentrations between the three groups whereas cord serum vaspin concentrations were significantly higher in SGA group $[\chi 2=8,158 p<0.05]$. Serum glucose and vaspin levels on postnatal 5 th day of life had no significant difference between three groups $[p<0.05]$. Circulating vaspin concentrations were not associated with sex of the infant and delivery route.

Conclusion Cord vaspin levels are significantly higher in SGA neonates than AGA or LGA neonates. The fetal programming hypothesis proposes that many adulthood diseases originate through adaptation which the fetus makes when it is undernourished. High cord vaspin levels in SGA infants may be one of the adaptation for increased risk for adult metabolic diseases.

\section{EVALUATION OF THYROID FUNCTIONS IN PRETERM NEWBORNS LESS THAN 34 WEEKS OF GESTATION}

doi:10.1136/archdischild-2012-302724.0651

'S Aball, ${ }^{2} \mathrm{~F}$ Baș, ${ }^{3} \mathrm{Z}$ Ince, ${ }^{2} \mathrm{R}$ Bundak, ${ }^{3} \mathrm{~A}$ Çoban. ${ }^{1 / s t a n b u l ~ U n i v e r s i t y ~ I s t a n b u l ~ M e d i c a l ~}$ Faculty; ${ }^{2}$ Paediatric Endocrinology; ${ }^{3}$ Neonatology, Istanbul University Istanbul Medical Faculty, Istanbul, Turkey

Objective To evaluate the thyroid functions of preterm infants. Methods Data about thyroid functions (fT4, TSH) were collected retrospectively from 428 preterm infants less than 34 weeks of gestation, who were born between 2006 and 2009.

Results The mean gestational age of the study group was $30.5 \pm 2.4$ (23.9-33.9) weeks, the mean birth weight was $1339 \pm 496$ (496-3190) 
g. The study group was divided into three subgroups according to gestational weeks ( $<28 \mathrm{wk}, \mathrm{n}=79 ; 28-316 / 7 \mathrm{wk}, \mathrm{n}=204$; 32-33 6/7 wk, $n=145$ ). Twenty five percent of the infants were small for gestational age (SGA). Mean age at first thyroid function evaluation was $18.3 \pm 12.5$ days. Mean fT4 levels were $12.0 \pm 3.1,14.1 \pm 3.3$ and $17.7 \pm 3.9 \mathrm{pmol} / \mathrm{L}$ in three subgroups, respectively and significantly lower in infants $<28$ weeks. In all subgroups SGA infants had lower fT4 levels, but it was significantly lower in only 28-31 6/7 and $32-336 / 7$ weeks but not in $<28$ weeks subgroup. Overall, the prevalence of hypothyroxinemia and hypothyroidism were $25 \%$ and $0.8 \%$, respectively in the first evaluation. $17.6 \%$ of infants $<28$ weeks had hypothyroxinemia $(n=13)$ and all of them were treated. In the total group levothyroxine treatment was given to 51 (11.9\%) infants. Mean treatment period was $1.6 \pm 1.2$ years.

Conclusion Free T4 levels were lower in the early gestational age subgroups. SGA infants had lower fT4 levels.

\section{PREVALENCE OF SENSORINEURAL HEARING LOSS IN PATIENTS WITH CONGENITAL HYPOTHYROIDISM}

doi:10.1136/archdischild-2012-302724.0652

'F Saffari, ${ }^{2} \mathrm{MH}$ Ababafha. 'Pediatrics, Oazvin University of Medical Sciences; ${ }^{2}$ Oazvin University of Medical Sciences, Oazvin, Iran

Background and Aims Congenital hypothyroidism is mainly diagnosed through neonatal screening program. Normal physical and mental development can be maintained with pertinent replacement therapy. One of the associated abnormalities in these patients is the sensorineural hearing defect, which has a prevalence of about $20 \%$ according to relevant references. The purpose of this study was to obtain the prevalence of sensorineural hearing loss in children with congenital hypothyroidism identified in the screening program in Qazvin, Iran.

Methods All patients afflicted with congenital hypothyroidism identified in the screening program (in Qazvin, Iran) were enrolled in this study. They were both under observed and hormonal replacement therapy by referral Endocrine Diseases Clinic and auditory brainstem responses test (ABR) was performed for all subjects.

Results Of 169 patients with congenital hypothyroidism, 42.3\% were female. The prevalence of sensorineural hearing loss was $5.3 \%$ (6 male, 2 female). Statistical analysis did not reveal any significant difference between the prevalence of sensorineural hearing loss with other variables of the study.

Conclusions A remarkable difference was observed between the results of our study with those stated in the references. Normal sensorineural hearing can be maintained with pertinent replacement therapy.

\section{PLACENTAL WEIGHT: RELATION TO MATERNAL WEIGHT AND GROWTH PARAMETERS AT BIRTH AND DURING CHILDHOOD}

doi:10.1136/archdischild-2012-302724.0653

A Soliman, M Eldabbagh, K Zahreldin, A Elawwa. Pediatrics, Hamad Medical Center, Doha, Oatar

Background Human growth is a continuous process. Studies defining placental effect on growth focus on discrete time points (e.g., birth), overlooking the conditional nature of the process.

Material and Methods Two hundred mothers who gave birth at term after an uncomplicated singleton pregnancy were studied using conditional analysis. Placental weight, infant length (BL), weight $(\mathrm{BW})$, and head circumference $(\mathrm{HC})$ were obtained at birth and during childhood period ( $4.5+/-2$ years) of age. Placental weight was correlated with growth parameters of the child at birth and during childhood.
Results At birth, placental weight was correlated significantly with maternal weight $(\mathrm{r}=0.21, \mathrm{p}=0.031)$, infant $\mathrm{BW}(\mathrm{r}=0.71, \mathrm{r}$ $<0.001)$, BMISDS( $\mathrm{r}=0.589, \mathrm{p}<0.001)$, LSDS (0.567, $\mathrm{p}<0.001)$, and $\mathrm{HC}(\mathrm{r}=0.699, \mathrm{p}<0.001)$. During childhood, placental weight was correlated with BMI SDS ( $r=0.296, p=0.002), \mathrm{HtSDS}=(\mathrm{r}=0.254$, $\mathrm{p}=0.009)$. Length SDS at birth was correlated significantly with HtSDS during childhood $(r=0.445, p<0.001)$.

Conclusion Placental weight is a good pointer of birth size (weight, length and HC) and may help forecast childhood growth.

\section{THE DIFFERENTIAL-DIAGNOSTIC FEATURES OF THELARCHE SYNDROME IN GIRLS}

doi:10.1136/archdischild-2012-302724.0654

V Buinitskaya, A Solntsava, 0 Zagrebaeva. Belarusian State Medical University, Minsk, Belarus

Aim To determine the most significant criteria in the diagnosis of true precoicois puberty and premature thelarche.

Methods 68 girls were analyzed in the endocrinological department in Minsk over 2003-2011 yrs. Group 1(G1) - girls with isolated thelarche (IT) (58 (85.3\%); group 2(G2) - with true precoicois puberty (TPP) (10 (14.7\%). Ultrasound $(\mathrm{u} / \mathrm{s})$ organs of the small pelvis, bone age, the levels of hormones (follicle-stimulating hormone $(\mathrm{FSH})$, luteinizing hormone (LH), estradiol (E2); gonadotropinreleasing hormone analogue $(\mathrm{GRH})$ stimulating test were conducted to all patients. Results were processed using the Statistica 6.1.

Results Breast development in G1: stages on Tanner 2 (84.3\%), 3 (15.7\%); G2: Tanner 2 (80\%), 3 (20\%). The onset of thelarche G1 $1.2 \pm 0.3$ yrs, G2 $5.3 \pm 0.77(\mathrm{p}=0.2)$. Bone age $(\mathrm{BoA}) /$ biological age $(\mathrm{Bia})$ G1 $0.63 \pm 0.08$ (< 1yrs), G2 3.3 \pm 0.01 . Uterus length G1 28.1 \pm 0.83 $(<35 \mathrm{~mm}), \mathrm{G} 235.4 \pm 2.9(\mathrm{p}=0.1)$. There was an excess of prepubertal ovaries norm ( $>0.2 \mathrm{ml})$ G1 $65 \%$, G2 $48 \%$ with the presence of follicules G1 20\%, G2 100\%. Basal FSH levels G1 4.73 \pm 0.52 (1.8-10.5 IU/L), G2 4.25 \pm 0.87 ( $p=0.3$ ); LH G1 0.76 \pm 0.13 (1-10 IU/L), G2 2 \pm 0.8 $(\mathrm{p}=0.15) ;$ E2 G1 $0.12 \pm 0.02(<0.5 \mathrm{ng} / \mathrm{ml}), \mathrm{G} 20.14 \pm 0.05(\mathrm{p}=0.08)$. There was a pubertal excess of LH levels in G2 (39.4 $20.4 \mathrm{IU} / \mathrm{L})$ by conducting GRH stimulating test.

Conclusions The differential diagnosis between TPP and IT are: advance $\mathrm{BoA}$ to $\mathrm{BiA}$, the excess of uterus length by $\mathrm{u} / \mathrm{s}$ and $\mathrm{E} 2$ levels, excess of LH levels by conducting stimulating test with $\mathrm{GRH}$ (which is the most important feature).

\section{GENDER PECULIARITIES OF THE COURSE OF GRAVES- BASEDOW DISEASE IN CHILDREN}

doi:10.1136/archdischild-2012-302724.0655

K Konchyts, A Solntsava, 0 Zagrebaeva. Paediatrics, Belarussian State Medical University, Minsk, Belarus

Aim To determine gender peculiarities of the course of GravesBasedow disease (GBD) in children depending on the sex and stage of puberty.

Methods We analyzed retrospectively 28 children with GBD in the endocrinological department of University hospital over the 2011 year (boys(B)/girls(G) 3/25, mean \pm SD age $13.15 \pm 3.03$ yrs). We conducted additional division on the subgroups of early (Tanner 2-3) and late (Tanner 4-5) puberty.

Results $67.8 \%$ children had complains (B losing weight $(66.7 \%)$; G weakness (32\%), heartbeat (24\%). Family history wasn't burdened in $33.3 \%$ B and $64 \%$ G. Relatives with diabetes mellitus type 1 was in $7.1 \%$ G; thyroid diseases $-33.3 \%$ B and $28 \%$ G; other endocrinopathies $33.3 \% \mathrm{~B}, 12 \% \mathrm{G}$. There was a tendency of more early manifestation GBD in G 12.94 \pm 3.07 yrs (B 14.86 \pm 2.42 yrs) ( $\Varangle>0.05)$. The onset of GBD was mainly in late puberty regardless of gender. There was lower TSH 0,085 $\pm 0.13(0.23-3.4 \mu \mathrm{IU} / \mathrm{l})$ and higher free T4 $62.13 \pm 34.34(10-23.2 \mathrm{pmol} / \mathrm{l})$ levels in B (G $0.12 \pm 0.2$ and 